\title{
THE PENN STATE PALEOCLIMATE SIMULATION LIBRARY: CALL FOR COLLABORATION
}

GIBBS*, Mark T.; BICE, Karen L., Earth System Science Center, Penn State University, University Park, PA 16802, U. S. A.; FAWCETT, Peter J., Dept. of Physics, University of Toronto, 60 St. George Street, Toronto, Ontario, M5S 1A7, Canada; BARRON, Eric J.; PETERSON, William H., Earth System Science Center, Penn State University, University Park, PA 16802, U. S. A.

Over the last three years, the Earth System Science Center at Penn State has conducted over 140 global climate simulations using an atmospheric general circulation model (GCM). We have investigated 13 time slices between the Late Permian and Present-Day, together with the Late Ordovician, Early Silurian and the Early, Middle and Late Devonian. Ocean GCM experiments have been performed for the Early Eocene and Present Day; Early Silurian and mid-Cretaceous experiments will soon be completed. Every experiment incorporates reconstructed paleogeography and continental topography or ocean bathymetry. For many time slices, we have also performed sensitivity tests for other geologically significant forcing factors (e.g. solar insolation, atmospheric $\mathrm{CO}_{2}$, orbital parameters, poleward ocean heat transport and vegetation cover). The atmospheric GCM (GENESIS v. 1.02A) produces predictions of the global distribution of temperature, moisture balance, winds, snow cover and other climate parameters over both diurnal and seasonal cycles. The ocean GCM (POCM) simulates the full annual cycle of water temperatures, salinities, and horizontal and vertical velocities.

This presentation serves as a summary of paleoclimate simulations available for comparison with the paleontological, sedimentological and geochemical record. We invite collaboration with workers familiar with extensive datasets that could be used to fully test the model. Close collaboration could yield many exciting insights into both data and models, and most importantly, establish where the models are performing well and where there are mismatches, a key aspect of continued model development and refinement.

The atmosphere and ocean GCMs provide excellent opportunities to compare, for example, local and regional environmental patterns derived empirically from the distribution of fossil assemblages against a physically-consistent numerical simulation of the paleoclimate. Local and regional environmental patterns derived from concentrated paleontological studies might in turn be considered against the global framework provided by the model results. For instance, predictions of oceanic circulation can be tested against patterns of endemism. In addition, although a GCM experiment defines an equilibrium climate for a specified set of boundary conditions, a sequence of simulations for different timeslices allows comparison against temporal trends in global climate, signals which are often readily discernible in the geologic record. 